\title{
Kemik grefti yerine geçen substratlar ve etki mekanizmaları
}

\section{Substrates that replace bone grafts and their action mechanisms}

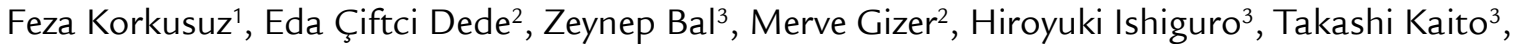 \\ Necdet Sağlam ${ }^{4}$, Petek Korkusuz
}

\author{
${ }^{1}$ Hacettepe Üniversitesi, Tıp Fakültesi, Spor Hekimliği Anabilim Dalı, Ankara, Türkiye \\ ${ }^{2}$ Hacettepe Üniversitesi, Fen Bilimleri Enstitüsü, Biyomühendislik Anabilim Dalı, Ankara, Türkiye \\ ${ }^{3}$ Osaka Üniversitesi, Tıp Fakültesi, Ortopedik Cerrahi Bölümü, Osaka, Japonya \\ ${ }^{4}$ Hacettepe Üniversitesi, Fen Bilimleri Enstitüsü, Nanoteknoloji ve Nanotıp Anabilim Dalı, Ankara, Türkiye \\ ${ }^{5}$ Hacettepe Üniversitesi, Tıp Fakültesi, Histoloji ve Embriyoloji Anabilim Dalı, Ankara, Türkiye
}

\begin{abstract}
Kazaların ülkemizde sık görülmesi, refah seviyesinin artmasıyla birlikte yaşlanan nüfusta görülen tümör ve metabolik hastalıklar, kemik rejenerasyonu için ileri biyomedikal teknolojik yaklaşımı zorunlu kılar. Oto-greft ve allogreftlerin uygulama sınırlamalarından dolayı, onarılması güç olan kemik dokusu kaybında, bazen tek başına veya klinik alanda kombinasyon halinde sentetik greftler ve kemik greftlerinin yerine geçecek substratlar kullanılır. Osteoindüksiyon ve kaplama ile sentetik materyallerin implant entegrasyonu amaçlansa da, son yıllarda nanoteknolojik ve moleküler biyolojik yaklaşımların geliştirilmesiyle birlikte, osteoindüksiyona yönelinmiştir. Kemik grefti yerine geçen substratların büyük bölümünü büyüme faktörleri oluşturur. Aktif sinyal molekülleri olarak da adlandırılan bu faktörler, doz ve zamana bağlı etki göstererek hücrelerin hasarlı dokuya yönlendirilmesi, ortamda çoğalması, farklılaşması ve daha sonra da ekstrasellüler matriksin yeniden yapılmasında görev alır. Kemik morfojenik proteinleri, aktif sinyal moleküllerinin en bilineni ve en çok çalışılanıdır. Bu proteinler, yeni kemik oluşumunu tetikleyen biyolojik olarak aktif moleküllerdir. Kemik yerine geçen substratların etkisini arttırmak, uygulandıkları ortamda uzun süre kalmalarını sağlamak ve kontrollü salınımlarının gerçekleştirilebilmesi için farklı biyomalzemeler taşıyıcı olarak kullanılabilmektedir. Bu derlemede de, kemik grefleri yerine kullanılabilen malzemeler, bunların sahip olması gereken özellikler ve çeşitli taşıyıcılarla beraber kullanımları ile kemik yeniden şekillenmesi ve rejenerasyonuna etkileri değerlendirilmiştir.
\end{abstract}

Anahtar sözcükler: kemik morfojenik protein (BMP); aktif sinyal molekülleri; büyüme faktörleri; biyoseramikler; kemik rejenerasyonu; kemik yeniden şekillenmesi
High-energy work and road traffic accidents as well as the increase in tumor rate and metabolic diseases entail an advanced biomedical approach to bone regeneration. In bone tissue loss, which is sometimes difficult to repair, due to application limitations of auto-grafts and allografts, synthetic grafts and substances that replace bone grafts are used alone, or in combination in the clinical field. Although implant integration of synthetic materials is aimed by osteoinduction and coating, with the development of nanotechnological and molecular biological approaches in recent years, osteoinduction is recently aimed. Growth factors constitute the majority of bone graft substitutes. These factors, also called active signal molecules, act by directing the cells to the damaged tissue, proliferating, differentiating and then reconstructing the extracellular matrix by showing dose and time dependent effect. Bone morphogenetic proteins are the most known and most studied of active signaling molecules. These proteins are biologically active molecules that trigger new bone formation. Different biomaterials can be used as carriers to increase the effect of bone substitute substrates, to ensure that they remain in their environment for a long time, and to achieve controlled release. In this review, the materials that can be used instead of bone grafts, the properties they should have, and their use with various carriers have been evaluated for bone remodeling and regeneration.

Key words: bone morphogenic protein (BMP); active signaling molecules; growth factors (GFs); bioceramics; bone regeneration; bone remodeling

- İletişim adresi: Prof. Dr. Feza Korkusuz, Hacettepe Üniversitesi, Tıp Fakültesi, Spor Hekimliği Anabilim Dalı, Sıhhiye, Ankara, 06100 Türkiye Tel: 0312 - 3051347 e-posta: feza.korkusuz@gmail.com

- Geliș tarihi: 1 Kasım 2017 Kabul tarihi: 1 Kasım 2017 
Ç. eşitli kazalara bağlı travmalar, kemik enfeksiyonları, tümörleri ve benzer nedenler ile oluşan kemik hasarları kemik greftleri ya da greft yerine geçen substratlar ile onarılmaktadır. Bu greftler ya da substratlar, osteointegrasyon, osteokondüktif veya osteoindüktiflik özelliklerinden en az birine sahip olmalıdır. ${ }^{[1]}$ Mekanik dayanımın istenilen düzeyde olması ve bölgenin damarlanması kemik rejenerasyonunda oldukça önemli kriterlerdir. Oto ve allogreftler onarımı sağlamalarına rağmen çeşitli dezavantajlara sahiptirler. Otogreftlerin ek bir operasyon ile elde edilmesi, donör bölgede ağrı ve enfeksiyon riskinin bulunması ve otogreftlerin yetersiz kalabilmesi, allogreftlerin ise immün yanıt oluşturabilecek olması, bu greftler yerine kullanılabilecek substratlara yönelime neden olmuştur.

Kemik grefti yerine geçen substratların büyük bölümünü büyüme faktörleri oluşturur. Mekanik ${ }^{[2]}$, manyetik ve elektriksel çevresel fiziksel etmenler, büyüme, tiroid, paratiroid gibi sistemik hormonlar, D vitamini $^{[3]}$, nöromediyatörler, endotelin ${ }^{[4]}$ ve başta kollajen 1 sentezini düzenleyen genetik yapı transforme edici büyüme faktörü beta'nın (TGF- $\beta$ ) alt grubu olan kemik morfojenik proteinler (BMP) olmak üzere, fibroblast büyüme faktörü (FGF), tümör nekroz faktör (TNF) ve trombosit kökenli büyüme faktörü (PDGF) üzerinden kemiği kontrol eder (Şekil 1). Bunlar aynı zamanda, aktif sinyal molekülleri olarak da adlandırılır. Mikrogram veya nanogram düzeyinde sentezlenerek ortama salınan ve çoğunlukla protein olan aktif sinyal molekülleri, çoğunlukla süreci veya diğer bir değişle kaskadı başlatarak ortadan kaybolur. Bu süreç çocukluk ve ergenlikte büyüme iken, ileri yaşlarda onarım ve rejenerasyon da aynı moleküller tarafından yönetilir. Doz ve zamana bağlı etki gösteren aktif sinyal molekülleri, hücrelerin hasarlı dokuya yönlendirilmesi, ortamda çoğalması, farklılaşmasında ve daha sonra da ekstrasellüler matriksin yeniden yapılmasında görev alır. Doğru molekülün, doğru zamanda ve doğru dozda sentezlenmesi önemlidir.

\section{KEMIK REJENERASYONU}

Kemik rejenerasyonu ve kırık onarımında kanlanma çok önemlidir. Anatomik redüksiyon, immobilizasyon ve kanlanmanın doğru sağlandığı kırık çoğunlukla kaynar. Kırık onarımı ve rejenerasyonunda öncül hücre osteoklasttır. Osteoblastlar osteoklast stimülasyonunu NF- $\kappa B$ reseptör ligandı (RANKL) salınımı ile desteklerken, aynı zamanda Osteoprotegerin (OPG) salınımıyla da NF-KB reseptörü (RANK)-RANKL etkileşimini engelleyerek osteoklast inhibisyonu yapar (Şekil 2). Yeniden kanlanmanın (neovaskülerizasyon) sağlanamadığı nekrotik dokuyu rezorbe eden osteoklastlar öncelikle endotelial hücreleri, osteoblast öncülü hücreleri ve osteoblastları kemik onarımını başlatmak üzere osteoprotegerin (OPG) salgılayarak uyarır. Osteositler ise, bu süreçte iletişimden sorumludur.

Kemik rejenerasyonu bir dizi dış ve iç etmene bağ|ı değişiklik gösterebilir. Kemik rejenerasyonunda kullanılan greftler ve yerine geçecek substratlar alıcının yaşından ve hastalıklarından etkilenir. Şeker hastalığı veya sarkom nedeniyle kemoterapi veya radyoterapi almakta olan hastada rejenerasyon geç ve güç olacaktır. Sigara kullananlarda da kırık geç kaynar..$^{[5]}$ Alıcının yaşı ve kemik niteliği de belirleyici faktörlerden birisidir. Kemik kütlesi, iç mimarisi ve iç malzeme özellikleri, kemiğin sağlamlığını ve kırığın iyileşmesini belirler. Osteoporoz hastalarında mineral ve kollajen konsantrasyonundaki azalma, kemiğin esnekliğinde, dayanıklığında ve elastik modülünde de azalmaya neden olur. Yaşla yavaşlayan hücre çoğalması ve şişmanlıkla artan vücut ödemi de kemik onarımını etkiler. Bu nedenle, alıcının kemik mikroçevresi greft yerine geçecek substratların da etkilerini belirleyecektir. Örneğin, ortamda düşük dereceli enfeksiyonun varlığı bu substratların etkisini azaltabilmektedir.

\section{KEMIK MORFOJENIK PROTEINLERI (Bone Morphogenic Protein-BMP)}

ilk kez 1965 yılında Dr. Marshal Urist tarafından tanımlanan kemik morfojenik proteinleri (BMP) ${ }^{[6]}$ aktif sinyal moleküllerinin en bilineni ve en çok çalışılanıdır. Biyolojik olarak aktif olan bu moleküllerin bazıları kemik oluşumunu tetiklemektedir. ${ }^{[7,8]}$ Bu proteinlerin, hücre çoğalması, farklılaşması ve ekstrasellüler matriksin yapılmasında görev aldığı bilinir; kemik onarımının yeniden şekillenmesinde de apopitozu kontrol ettikleri belirtilir. ${ }^{[9]}$ Kemik grefti yerine geçen substratların hücre duvarındaki membran reseptörleri ve hücre içi sinyal mekanizmaları aydınlatılmıştır. ${ }^{[10]}$ Alfa ve beta integrinler, başta kalsiyum, sodyum, potasyum ve klor olmak üzere, iyon kanalları ve $\mathrm{G}_{\mathrm{s}}-\mathrm{G}_{\mathrm{q}}$ reseptörlerine bağlanan substratlar, hücre içi aktin ve miyozin aracılığıyla hücre çekirdeğini uyararak, NF-אB başta olmak üzere transkripsiyon faktörleri aracılığıla hücresel yanıtı ve ekstrasellüler matriks yapımını başlatır. Bu substratlara duyarlı membran reseptörleri osteoblast ve kondroblast dışında osteoklastlarda da bulunduğundan, bunların kemik ve kıkırdağın homeostazında da görev aldığı söylenebilir. Dışarıdan uygulanan substrat dozu genellikle yüksek tutulur. Özellikle, BMP'nin kök hücrenin yaralı bölgeye göçünü arttırdığı belirtilir. Hipertrofik kaynama yokluğunda BMP'nin etki mekanizması kök hücre göçüyle açılanmaya çalışılmakla birlikte, bu hücrelerin ortamda bulunmadığı atrofik kaynama yokluğunda etkinin nasıl oluştuğu bilinmemektedir. Ektopik kemik oluşumunun indükleyicisi 


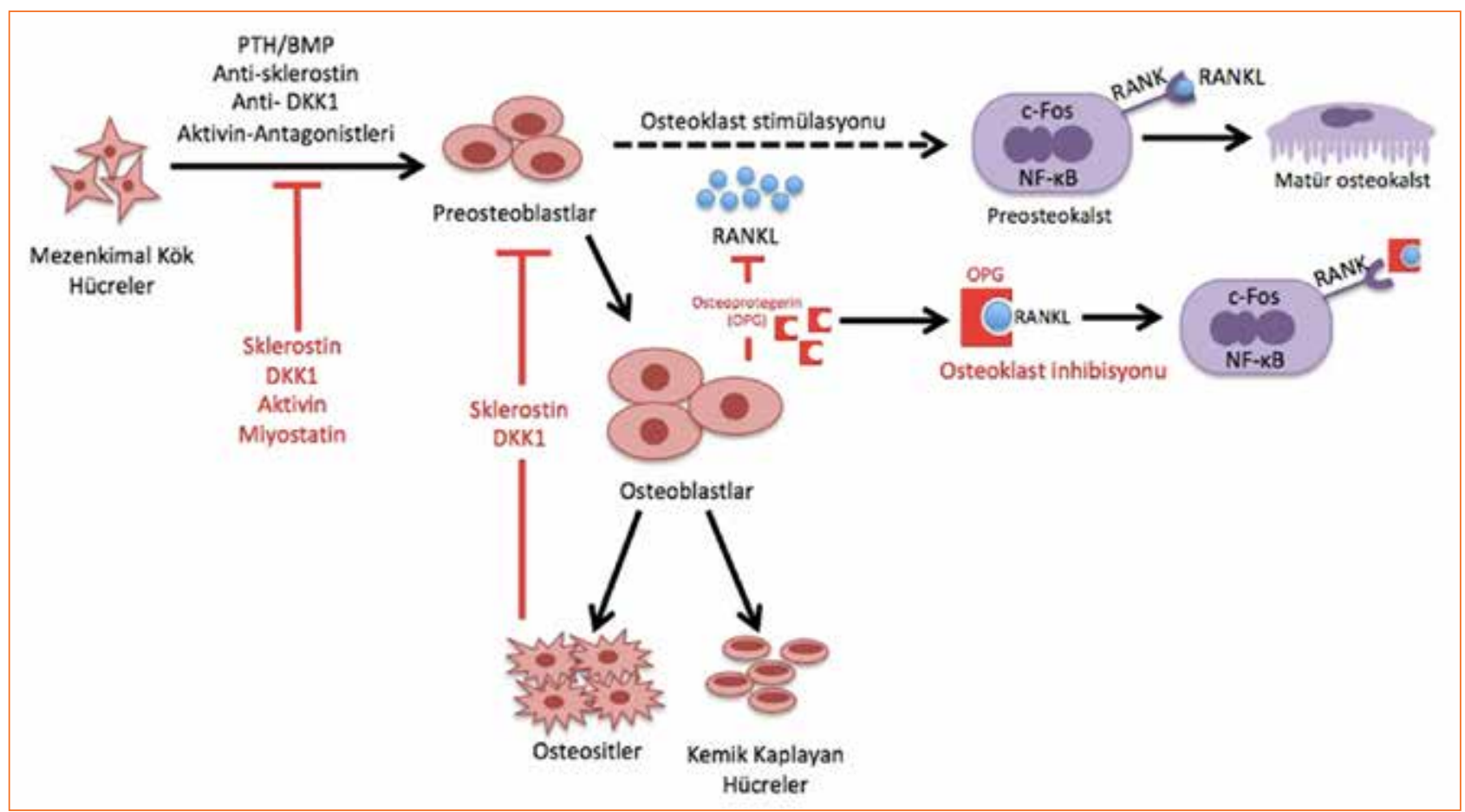

Şekil 1. Mezenkimal kök hücrelerin osteoblastlara farklılaşmasındaki önemli sinyal molekülleri, bunların birbirleri ile etkileşimleri ve sinyal ağları şeması.

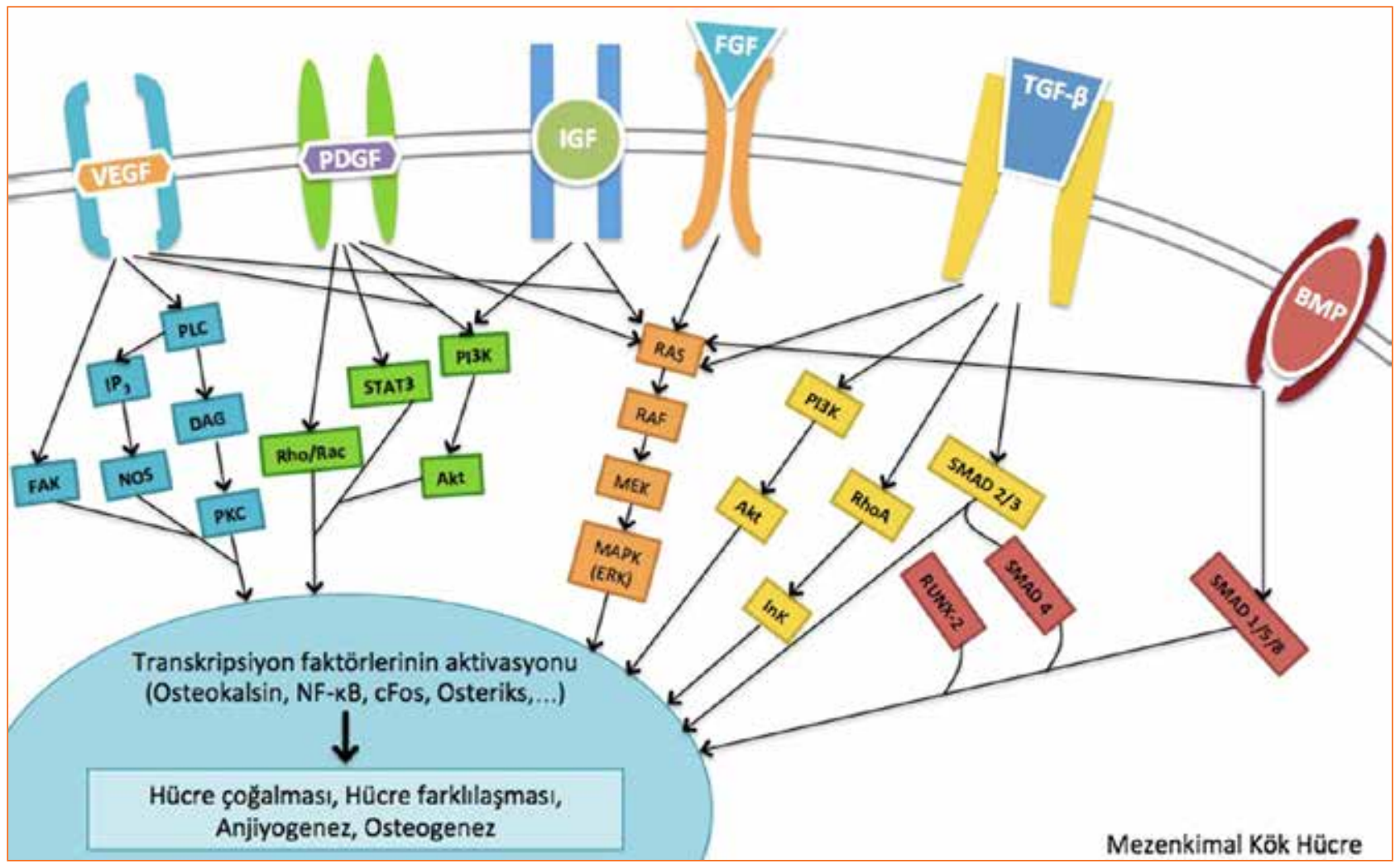

Şekil 2. Kemik rejenerasyonu ve yeniden şekillenme mekanizması şeması. Parathormon (PTH), kemik morfojenik protein (BMP) gibi çeşitli sinyal molekülleri osteoblast farklılaşmasını tetiklerken DKK1, sklerostin, aktivin ve miyostatin farklılaşmayı engeller. Osteoblastlar osteoklast stimülasyonunu RANKL salınımı ile desteklerken aynı zamanda Osteoprotegerin (OPG) salınımıyla RANK-RANKL etkileşimini engelleyerek osteoklast inhibisyonu yapar. 
olarak tanımlanan BMP'lerin, kemik oluşumunda, kemik rejenerasyonunda, kırık iyileşmesinde ve osteofit oluşumunda önemli etkileri olduğu bilinir. ${ }^{[11]}$ BMP2'nin in vitro ortamda farklılaşmamış mezenkimal hücrelerin, miyoblastların ya da osteoprogenitör hücrelerin osteoblastlara farklılaşmasında etkili olduğu rapor edilmiştir. ${ }^{[12]}$

Günümüzde BMP, spinal füzyonda, zor kaynayan kırıklarda ve kemik defekti onarımında kullanılmaktadır. Zor kaynayan kırıkların başında tibia 1/3 distal bölge kırıkları tanımlanmıştır. ${ }^{[13]}$ Tümör, enfeksiyon ve hamilelerde kullanılması ise endikasyon dışıdır. Çocuk ve genç erişkinlerde kullanımı ise tartışmalıdır. Başta BMP olmak üzere kemik grefti yerine geçen substratların bir bölümü ticari ürün olarak bulunup hastalarda kullanılmaktadır, ancak bu durumda hasta seçimi önemlidir. ${ }^{[14]}$ Kemik grefti yerine geçecek olan ürünlerin gelecekte doku mühendisliği alanında daha yaygın kullanılması söz konusudur. Kemik morfojenik protein ve diğer kemik grefti yerine geçen substratların kullanıldığı olgularda mekanik sağlamlığın kırık bölgesinde korunuyor olması gerekir. Ancak, implant varlığında bunların kullanılması deneysel verilerin başarısında bağlıdır. Kemik morfojenik proteinin anjiyojenik faktörlerle ${ }^{[15,16]}$, paratiroid hormonla ${ }^{[17]}$ ve mezenkimal kök hücrelerle birlikte kullanılması ${ }^{[18,15]}$ söz konusudur. Kemik grefti yerine geçen substratlar tek başına da kullanılabilmekle birlikte, çoğunlukla iyileşmeyi yönlendiren hücre ve biyomalzemelerle birlikte kullanilır. Günümüzün önemli araştırma konularından birisi; kemik grefti yerine geçen substratların, skafoid, talus boyun, tibia distal uç gibi zor kaynayan bölgelerde kırığın belirlendiği anda kullanılabilmesidir. Yine güncel araştırma konularının başında; diyabet, vasküler yetmezlik, çoklu travma, enfeksiyon, osteoporoz ve osteoartrit gibi sistemik hastalıklarda gelişen kırıklarda bu substratların kullanılması gelmektedir. Kemik grefti yerine geçen substratların dokuda etkili olabilmesi için, hücre duvarındaki reseptörlerinin ve hücre içi sinyal moleküllerinin de iyi anlaşılması gerekir.

Onarım ve rejenerasyonda BMP'nin doğru doz ve zamanda kırık bölgesine verilebilmesinin değerlendirilebilmesi için, Seo ve ark. ${ }^{[19]}$ beş farklı hidrojel formülasyonundan salınım çalışması gerçekleştirmiş ve hidrojelden BMP'nin hızlı çıkışının rejenerasyon için yeterli olmadığı, geç salan hidrojel formülasyonunun da etkiyi baskıladığı gösterilmiştir. Lopez-Cebral ve ark. da ${ }^{[20]}$ yeni hidrojeller ile BMP-2'nin taşınmasını çalışmıştır. Hidrojeller, son yıllarda BMP'nin taşınması için ideal malzemeler olarak görülmekle birlikte, suda hızlı çözünmeleri BMP'nin erken salınmasına neden olur. Bu nedenle, bir çalışmada ${ }^{[21]}$ katyonik stearilamin ve kollesterol kullanılarak fare kraniyal defektlerinin onarımı için siRNA yaralı bölgeye taşınmıştır. Kemik morfojenik proteinin kemik rejenerasyonu bölgesine doğru taşınması için çok sayıda in vitro ve in vivo çalışma yapılmış ve yayımlanmıştır. ${ }^{[22]}$ Rekombinant - insan kemik morfojenik protein 2 (rhBMP2)'nin çapraz bağ içermeyen pegile poli-gliserol sebakat (PEGS) ile kaplı mezoporöz biyocam kompozit hücre iskeleleri ile taşınması hem in vitro hem de in vivo olarak değerlendirilmiş, PEGS'in rhBMP2'nin kontrollü salınımını sağlayarak, hızlı kemik oluşumunu desteklediği bildirilmiştir. ${ }^{[23]}$

Kemik morfojenik proteinle gerçekleştirilen klinik çalışmaların bir bölümünde örneklem sayısı düşüktür ve kontrol grubu bulunmamaktadır. ${ }^{[24,25]} \mathrm{Bu}$ araştırmalarda BMP oto- veya allogreftle birlikte kullanıldığından, etkinin substrattan mı yoksa greftin kendisinden mi geldiği ayırt edilememektedir. Diğer taraftan, otogreftlerin ve allogreftlerin komplikasyonları iyi bilindiğinden, kemik grefti yerine geçen substratlar klinikte giderek önem kazanmaktadır. Kemik morfojenik proteinle ilgili klinik çalışmalar ${ }^{[26-28]}$ ameliyatta kan kaybını 43 ila $336 \mathrm{ml}$ azalttığı ve ameliyat süresini 9 ila 15 dakika kısalttığını göstermektedir. Bu çalışmalarda istatistiksel olarak anlamlı sonuçlara ulaşılmış olmakla birlikte, klinik önemleri gelecekte yapılacak çalışmalarla ortaya konabilecektir. Bu substratlarla ilgili güvenlik, etkinlik ve güvenirlik çalışmaları bu nedenle önemlidir. Ayrıca, kemik morfojenik proteinin enfeksiyonu nasıl azalttığı ve hastanın yaşam kalitesini nasıl arttırdığının araştırılması da önemlidir.

Son yıllarda BMP'ye bağlı komplikasyonlar da bildirilmiştir. Bir koyun çalışmasında ${ }^{[29]}$ inflamatuvar hücrelerle birlikte BMP'ye karşı serum antikorlarının arttığı, bunun da vücutta genel ödeme neden olarak kemikte aşırı büyüme ile heterortopik ossifikasyona neden olduğu bildirilmiştir. ${ }^{[30]}$ Klinik çalışmalara bağlı komplikasyonlar; yumuşak dokularda hematom oluşumu, proksimal humerus kırıklarında aşırı inflamasyon, kemik kisti oluşumu ve açık tibia kırıklarında enfeksiyon olarak bildirilmiştir. ${ }^{[31]}$ Aynı derlemede, yan etkiyi azaltmak üzere düşük doz BMP kullanıldığında da açık tibia kırıklarında kaynamamanın \%44 oranında arttığı belirtilmiştir. Bir ürün için ise sekiz kanser olgusu bildirildiğinden, başta BMP olmak üzere kemik grefti yerine geçen substratların kas-iskelet sistemindeki olası yan etkilerinin bilinmesinde yarar vardır. Kemik morfojenik proteinin endikasyonları giderek çoğalmaktadır ${ }^{[32]}$, ancak skafoid kemik[33] ve talus gibi zor kaynadığı bilinen kemiklerin rejenerasyonunda BMP'nin yararlığı konusunda sınırlı sayıda çalışma yayımlanmıştır. Kemik grefti yerine geçen substratların doku mühendisliği uygulamalarında yakın gelecekte daha fazla kullanılması beklenmektedir. ${ }^{[10]}$ Doku mühendisliğinde hücreler, taşıyıcı matriksler ve sinyal moleküllerinin birlikte 
kullanılması söz konusudur. Kemik grefti yerine geçen substratların dokuya taşınmasında kullanılacak taşıyıcılara yönelik araştırmalar ${ }^{[34,35]}$ sürmektedir. Virüs içermeyen ve kemik grefti yerine geçen substratların genini taşıyabilecek yöntemler güncellik kazanmaktadır. Gen aktive matriks olarak adlandırılan bu yaklaşımla, kırık iyileşmesi veya kemik rejenerasyonunda tüm molekülün taşınması yerine, kilit proteinin yaralı bölgeye verilerek içeride sentezin tetiklenmesi hedeflenmiştir. ${ }^{\left[{ }^{[6]}\right.}$

\section{KEMIK GREFTI YERINE GEÇEN SUBSTRATLARIN TAŞIYICILARLA UYGULANMASI}

Kemik yerine geçen substratların etkisini arttırmak ve uygulandıkları ortamda uzun süre kalmalarını sağlamak için farklı biyomalzemeler taşıyıcı olarak kullanılabilir. Son yıllarda kullanılan nano-hidroksiapatit toz veya granüller bu biyomalzemelerin başında gelir. Bir çalışma ${ }^{[37]}$ laktoferinin nano-hidroksiapatit rod ve mikrokürelerle birlikte kullanıldığında kemik rejenerasyonunu arttırdığını göstermiştir. Benzer bir çalışmada Gao ve ark., laktoferinin kemik rejenerasyonundaki etkisini değerlendirilmiş, laktoferin içeren grupların, karşılaştırılan gruplardan daha yüksek kemik hacmi fraksiyonu ve yeni kemik oluşumunu geliştirdiği gözlenmiştir. ${ }^{[38]}$ Başka bir çalışmada da ${ }^{[39]}$, kalsiyum fosfat, jelatin ve ipek-fibroin kullanılarak geliştirilen mekanik dayanıklığı yüksek biyomalzemenin hücre kültürü ortamında MG63 hücrelerinin çoğalmasını arttırdığı belirlenmiştir. Başka bir tavşan çalışmasın$\mathrm{da}^{[40]}$, ipek-fibroin karbon nano-liflerle güçlendirilerek BMP ve TGF- $\beta$ kemik defektine birlikte uygulanmış ve başarılı sonuç elde edilmiştir. Paratiroid hormon (PTH), kemiğin dengesini sağlayan en önemli sistemik hormonlardan birisidir ve osteoporoz tedavisinde kullanılır. Dang ve ark. ${ }^{[41]}$ biyomimetik nanofibröz bir ağ kullanarak PTH'nın kırık bölgesine atımlar halinde uygulanmasını sağlamış ve bunun farelerde PTH'ya bağlı olası yan etkileri azaltarak kritik boyuttaki defektte kemik rejenerasyonu sağladığını göstermiştir. Nanoteknoloji ve nanotıbbın gelişmesi, özellikle kemiğe afinitesi olan bifosfonat ve tetrasiklin veya bunların bileşiklerinin kemiğe PTH gibi substratların eklenmesine katkı vermiştir. ${ }^{[42]} \mathrm{Bu}$ yaklaşımla, özellikle osteoporoz hastalarında büyük moleküllerin böbrek gibi organlardaki olası hasarlarının önüne geçilmesine çalışılmaktadır.

Vücut içine uygulandıklarında katılaşan jelatin bazI hidrojeller de ${ }^{[43]}$ kemik grefti yerine geçen substratların taşınmasında yaygın kullanılır. Bu hidrojeller üç boyutlu biyolojik yazıcılarda kullanıldığında hücre ile birlikte doku baskısı yapabildiklerinden, doku mühendisliği yaklaşımları için önemli bir malzeme grubunu oluşturmaktadır. Domuz veya dana derisi ya da kemiğinden elde edilen jelatin önceleri yaygın olarak kullanılırken, buna bağlı gelişen vücut tepkimesi ${ }^{[44]}$ son yıllarda klinikte kullanımını azaltmıştır. Ancak jelatin günümüzde kollajenin zor bulunduğu koşullarda sistem optimizasyonu amacıyla yaygın olarak kullanılmaktadır. ${ }^{[45]}$ Rekombinant teknoloji ile saflı̆gı yüksek jelatinin üretilmesiyle, hayvan kökenli malzemenin sorunları aşılabilir. Çözünmenin gecikmesi için çapraz bağlama gerekir. Hidrojeli çapraz bağlayarak bunların sıvı ortamda çözünmesi yavaşlatıldığında, hem hücrelerin hem de aktif sinyal moleküllerinin taşınması için ideal malzeme yapısına ulaşılabilir. Çapraz bağlama için mikrodalganın kullanılması basit ve ucuz bir yöntemdir. Hidrojeller, yine son zamanların gelişen teknolojisi olan elektron-eğirtme (electrospinning) sisteminde de yaygın kullanılır. ${ }^{[45]} \mathrm{Bu}$ yaklaşımla, örneğin, yerel nüksün önlenebilmesi için implant kaplamasına antikanser ilaçlarının eklenmesi başarılmıştır. Çalışmalar, bu hidrojellerin BMP-2, IGF ve bFGF'nin kemik rejenerasyonu bölgesine taşınması aşamasında da kullanıldığını göstermektedir. Örneğin, bFGF'in gözenekli hidroksiapatit granül ve jelatin hidrojel mikroküre ile tavşan kraniyal defektine uygulandığı bir çalışmada ${ }^{[46]}$ başarılı sonuç bildirilmiştir.

Nanoteknolojinin tıp alanında kullanılması, kemik yerine geçen substratların onarım bölgesine taşınmasına yardımcı biyomalzemelerin geliştirilmesine katkı vermiştir. Nanomalzemelerin başında nano-hidroksiapatit (nHAp) gelmektedir. nHAp'ın doku ile temas eden yüzey alanının geniş olması ve mikron boyutundaki eşdeğerlerine göre düşük doku yanıtı oluşturma özelliği bulunmaktadır. ${ }^{[47]} \mathrm{nHAp}$ yakın geçmişte, kök hücrelerin yaralı bölgeye taşınmasında ${ }^{[48]}$, strontium veya boron gibi eser elementlerin kemik hücrelerini uyarıcı etkilerinin incelenmesinde ${ }^{[49]}$ ve osteomiyeliti önlemek amacıyla kontrollü vankomisin salınımın$\mathrm{da}^{[50]}$ kullanılmıştır. Yakın geçmişte tamamlanan bir çalışmada ${ }^{[51]}$, nHAp'ların özellikle nano-küre formunda olanlarının kemik defekti onarımında daha etkili olduğu gösterilmiştir. Bu nedenle, kemik yerine geçen substratların taşınmasında nHAp'ın sferik formlarının tercih edilmesi önerilmektedir.

Taşıyıcı kullanıldığında, BMP'nin tek başına kullanıldığında gereken dozdan daha düşük dozlarda etkili olabileceği gösterilmiştir. ${ }^{[52,8]}$ BMP'nin taşınmasında kullanılan çeşitli malzemeler ve kullanım formları Tablo 1'de özetlenmiştir.

Kemik morfojenik proteinlerinin, kemik rejenerasyonunu başlatıp sürdürmesi için optimum dozda salınmasının sağlanması önemli olmakla birlikte, yüksek doz BMP'nin inflamasyona, yumuşak doku ödemine ve istenmeyen kemik oluşumlarına neden olduğu da 
Tablo 1. BMP taşıyıcı malzemeler ve kullanım formları

\begin{tabular}{|c|c|c|c|}
\hline Malzeme türü & \multicolumn{2}{|c|}{ Malzeme çeşidi } & Kullanım şekli \\
\hline \multirow[t]{7}{*}{ Doğal polimerler } & \multicolumn{2}{|l|}{ Kollajen } & Toz, membran filmler, sulu form, jel, nanofiber, putty, sünger \\
\hline & \multicolumn{2}{|c|}{ Hiyaluronik asit/Hyaluronan } & Jel, hücre iskelesi, sulu form \\
\hline & \multicolumn{2}{|l|}{ Jelatin } & Hidrojel, kompozit hücre iskelelerinde mikroparçacık \\
\hline & \multicolumn{2}{|l|}{ Fibrin } & Hidrojel \\
\hline & \multicolumn{2}{|l|}{ Kitosan } & Film \\
\hline & \multicolumn{2}{|l|}{ Aljinat } & Sulu form \\
\hline & \multicolumn{2}{|l|}{ İpek } & Film, 3 boyutlu poröz hücre iskelesi, mikroparçacık \\
\hline \multirow[t]{8}{*}{ Sentetik polimerler } & \multicolumn{2}{|c|}{ PLA (poli-laktik asit) } & Sulu form, yeniden şekillendirilebilir implantlar \\
\hline & \multicolumn{2}{|c|}{ PGA (poliglikolik asit) } & $\begin{array}{l}\text { Örgü formunda olmayan PGA fiberler, hücre iskeleleri ve nano } \\
\text { parçacıklar }\end{array}$ \\
\hline & \multicolumn{2}{|c|}{ PLGA poli (D, L-laktid-ko-glikolid) } & Mikroparçacıklar, implantlar, 3 boyutlu hücre iskeleleri, kapsüller, jeller \\
\hline & \multicolumn{2}{|c|}{ PEG (poli-etilenglikol) } & Hidrojel \\
\hline & \multicolumn{2}{|c|}{ PCL (poli-kaprolakton) } & Üç boyutlu hücre iskelesi \\
\hline & \multicolumn{2}{|c|}{ PPF (poliproplen-fumarat) } & Poröz hücre iskelesi \\
\hline & Blok Polimer & PLA-PEG & Peletler \\
\hline & & PLA-DX-PEG & İmplantlar \\
\hline \multirow[t]{3}{*}{ İnorganik malzemeler } & \multicolumn{2}{|l|}{ Hidroksiapatit } & Fiber kafes, sement, poröz hücre iskelesi \\
\hline & \multicolumn{2}{|c|}{ TCP (trikalsiyum fosfat) } & Poröz multisilindir hücre iskeleleri, sement, granüller \\
\hline & \multicolumn{2}{|c|}{ BCP (bikalsiyum fosfat) } & Hücre iskeleleri \\
\hline
\end{tabular}

bilinmektedir. ${ }^{[48]}$ Kaito ve ark., BMP taşıyıcısı olarak PLA-PEG blok kopolimeri kullanmışlar ve rekombinant insan BMP-2 (rhBMP-2) için bu kompozitin, etkili bir taşıyıcı olduğunu vurgulamışlardır. Yüksek doz rhBMP-2'nin ilk dört haftada implant çevresinde kemik oluşumunu tetiklediği belirtilmişse de, operasyon sonrası sekiz haftada düşük dozda BMP uygulanmasının histolojik, biyomekanik ve radyografik etkilerinin aynı olduğu gösterilmiştir. ${ }^{[52]}$ Bu nedenle, BMP 2'nin kontrollü salınımının yapılabilmesi için çeşitli taşıyıcılar kullanılabilmektedir. Bu taşıyıcılardan PLA-PEG, biyouyumlu ve biyoçözünür bir polimerdir. BMP ile birleştirilmiş PLA-PEG, in vivo ortamda hidrojel yapısı oluşturur. Hettiaratchi ve ark.'nın yapmış oldukları bir çalışmada ise BMP-2'nin hızlı salınımının önüne geçmek için PCL nano-fiber ızgara tüpler ve heparin mikropartiküller ile kollajen hücre iskeleleri geliştirilmiştir. BMP-2'nin bağlanma ve salınım özelliklerinin incelendiği in vitro çalışmalarda, BMP-2'nin bağlanma potansiyelinin arttığı ve tüplerden salınımının azaldığı görülmüştür. Ancak in vivo çalışmalarda, ratlarda kritik boyutlu femoral segmental hasar modeli oluşturularak, üretilen malzemenin hasarlı bölgenin remineralizasyonu ve heterotopik ossifikasyonuna etkileri incelendiğinde, hipotezinin aksine mekanik özellikler, yenilenmiş kemik hacmi ve ossifikasyon değerleri açısından anlamlı bir etki gözlenmemiştir. ${ }^{[53]}$

\section{KEMIK YERINE GEÇEBILECEK SUBSTRATLARIN MAALIYET DEĞERLENDIRMESi}

Tahmin edilebileceği üzere, kemik grefti yerine geçen substratların üretilerek klinikte kullanılmasının maliyeti yüksektir. ${ }^{[54]}$ Örneğin, skolyoz cerahisinde bir segmentte füzyonun sağlanabilmesi için kullanılacak BMP'nin maliyeti tüm cerrahinin maliyetini doğrudan etkilemekle birlikte, bazı olgularda kullanılması gerekmektedir. Amerika Birleşik Devletleri'nde, BMP'nin bir hastada kullanılabilecek miktarı $3 \mathrm{mg} / \mathrm{ml}^{\prime}$ yi geçmemelidir. Bu nedenle, füzyon bölgesinin iyi belirlenerek optimum BMP kullanımına özen gösterilmelidir. Kemik morfojenik proteinin üretiminde, yeni teknolojinin kullanılmasıyla birlikte maliyetlerin azalması öngörülmektedir.

Sonuç olarak; başta BMP olmak üzere kemik grefti yerine geçen substratlar, tek başlarına veya taşıyıcı biyomalzemelerle birlikte, son yıllarda özellikle kemik 
onarımı veya rejenerasyonun sorunlu olduğu hastalık veya yaralanmalarda giderek artan oranlarda kullanılmaya başlanmıştır. Özellikle, otogreftin alındığı donör bölgesindeki ağrı, sinir yaralanması, enfeksiyon gibi sorunlar, bu substratların kullanımını arttırmıştır. BMP'nin klinikteki kullanım dozu önemlidir. Düşük dozda BMP verilmesi etkiyi azaltırken, yüksek dozda BMP istenmeyen ossifikasyona neden olur. BMP'nin osteoindüktif taşıyıcılarla kullanılmasının nedeni olası yan etkileridir. Farklı taşıyıcılar kullanılmış olmakla birlikte, son yıllardaki araştırmalar bunların polimer ve nano-hidroksiapatit biyoseramik kompozitlerle taşınmasının doğru olacağını gösterir yöndedir. Diğer bir yaklaşım da, BMP'nin tüm protein dizininin verilmesi yerine etkili fragmanlarınını uygulanmasıdır. Yakın gelecekte, bazı primer yaralanmalarda veya kaynama yokluğu olgularında kemik grefti yerine geçen substratların klinikte artan oranlarda kullanılması beklenmektedir; araştırmalar da bu doğrultuda sürdürülmektedir.

\section{KAYNAKLAR}

1. Şimşek A, Çakmak G, Cila E. Kemik greftleri ve kemik greftlerinin yerini tutabilecek maddeler. TOTBID Derg 2004;3.

2. Uslu MM, Bozdogan Ö, Güney S, Bilgili H, Kaya Ü, Olcay $B$, Korkusuz F. The effect of extracorporeal shock wave treatment (ESWT) on bone defects: an experimental study. Bull Hosp Joint Dis 1999;58:114-8.

3. Ömeroğlu $H$, Ömeroğlu $S$, Korkusuz F, Ateş Y. Effect of 25-OH-vitamin D on fracture healing in elderly rats. J Orthop Res Off Publ Orthop ResSoc 1999; 17:795.

4. Muratlı HH, Tabak AY, Korkusuz P, Örs Ü, Korkusuz F, Ercan S. Endotelin antagonisti bosentanın kırık iyileşmesi üzerindeki etkisinin kobay modelinde incelenmesi. İnsizyon 1999;2:171-80.

5. Yorgancıgil $H$, Özerdemoğlu RA, Korkusuz F, Erdoğan N, Mumcu EF. The effects of nicotine on fracture healing in rats. J Musculoskeletal Res 1998;2:289-96.

6. Urist MR. Bone: formation by autoinduction. Science 1965;150:893-9.

7. Kaneko K, Higuchi C, Kunugiza Y, Yoshida K, Sakai T, Yoshikawa H, Nakata K. Hyaluronan inhibits BMP-induced osteoblast differentiation. FEBS Lett 2015;589:447-54. Crossref

8. Morimoto T, Kaito T, Kashii M, Matuso Y, Sugiura T, Iwasaki $M$, Yoshikawa $\mathrm{H}$. Effect of intermittent administration of teriparatide (PTH1-34) on BMP-induced bone formation in a rat spinal fusion model. J Bone Joint Surg Am 2014;96:e107. Crossref

9. Li X, Cao X. BMP Signaling and skeletogenesis. Ann N Y Acad Sci 2006;1068:26-40. Crossref

10. Bessa PC, Casal M, Reis RL. Bone morphogenetic proteins in tissue engineering: the road from the laboratory to the clinic, part I (basic concepts). J Tissue Eng Regen Med 2008;2:1-13. Crossref

11. Hong $Y$, Fan H, Li B, Guo B, Liu M, Zhang X. Fabrication, biological effects and medical applications of calcium phosphate nanoceramics. Mater Sci Eng R Rep 2010;70:22542. Crossref
12. Dimitriou R, Jones E, McGonagle D, Giannoudis PV. Bone regeneration: current concepts and future directions. BMC Med 2011;9:66. Crossref

13. U.S. National Library of Medicine. ClinicalTrials.gov. Available at: https://www.clinicaltrials.gov

14. Hood L. A doctor's vision of the future of medicine. Newsweek, July 6/ July 13: 50, 2009. Available at: http://www.newsweek. com/doctors-vision-future-medicine-80793

15. Huang YC, Kaigler D, Rice KG, Krebsbach PH, Mooney DJ. Combined angiogenic and osteogenic factor delivery enhances bone marrow stromal dell-driven bone regeneration. J Bone Miner Res 2005;20:848-57. Crossref

16. Patel ZS, Young S, Tabata Y, Jansen JA, Wong ME, Mikos AG. Dual delivery of an angiogenic and an osteogenic growth factor for bone regeneration in a critical size defect model. Bone 2008;43:931-40. https://doi.org/10.1016/j. bone.2008.06.019

17. Morgan EF, Mason ZD, Bishop G, Davis AD, Wigner NA, Gerstenfeld LC, Einhorn TA. Combined effects of recombinant human BMP-7 (rhBMP-7) and parathyroid hormone (134 ) in metaphyseal bone healing. Bone 2008;43:1031-8. Crossref

18. Fu TS, Chen WJ, Chen LH, Lin SS, Liu SJ, Ueng SW. Enhancement of posterolateral lumbar spine fusion using low-dose rhBMP-2 and cultured marrow stromal cells. J Orthop Res 2009;27:380-4. Crossref

19. Seo BB, Koh JT, Song SC. Tuning physical properties and BMP-2 release rates of injectable hydrogel systems for an optimal bone regeneration effect. Biomaterials 2017;122:91104. Crossref

20. López-Cebral R, Civantos A, Ramos V, Seijo B, LópezLacomba JL, Sanz-Casado JV, Sanchez A. Gellan gum based physical hydrogels incorporating highly valuable endogen molecules and associating BMP-2 as bone formation platforms. Carbohydr Polym 2017;167:345-55. Crossref

21. Cui ZK, Sun JA, Baljon JJ, Fan J, Kim S, Wu BM, Aghaloo T, Lee M. Simultaneous delivery of hydrophobic small molecules and siRNA using Sterosomes to direct mesenchymal stem cell differentiation for bone repair. Acta Biomater 2017;58:21424. Crossref

22. Segredo-Morales E, Garcia-Garcia P, Evora C, Delgado A. BMP delivery systems for bone regeneration: Healthy vs osteoporotic population. Review. J Drug Delivery Sci Technol 2017;42:107-18. Crossref

23. Chai $Y$, Lin D, Ma Y, Yuan Y, Liu C. RhBMP-2 loaded MBG/ PEGylated poly (glycerol sebacate) composite scaffolds for rapid bone regeneration. J Mater Chem B 2017;5:4633-47. Crossref

24. Granjeiro JM, Oliveira RC, Bustos-Valenzuela JC, Sogayar MC, Taga R. Bone morphogenetic proteins: from structure to clinical use. Braz J Med Biol Res 2005;38:1463-73. Crossref

25. McKay WF, Peckham SM, Badura JM. A comprehensive clinical review of recombinant human bone morphogenetic protein-2 (INFUSE ${ }^{\circledR}$ Bone Graft). Int Orthop 2007;31:72934. Crossref

26. Burkus JK, Gornet MF, Dickman CA, Zdeblick TA. Anterior lumbar interbody fusion using rhBMP-2 with tapered interbody cages. J Spinal Disord Tech 2002;15:337-49.

27. Friedlaender GE, Perry CR, Cole JD, Cook SD, Cierny G, Muschler GF, Zych GA, Calhoun JH, LaForte AJ, Yin S. Osteogenic protein-1 (Bone Morphogenetic Protein-7) in the treatment of tibial nonunions. J Bone Joint Surg Am 2001;83A Suppl 1:S151-8. 
28. Jones AL, Bucholz RW, Bosse MJ, Mirza SK, Lyon TR, Webb LX, Pollak AN, Golden JD, Valentin-Opran A. Recombinant human BMP-2 and allograft compared with autogenous bone graft for reconstruction of diaphyseal tibial fractures with cortical defects. A randomized, controlled trial. J Bone Joint Surg Am 2006;88:1431-41. Crossref

29. Egermann M, Lill CA, Griesbeck K, Evans CH, Robbins PD, Schneider E, Baltzer AW. Effect of BMP-2 gene transfer on bone healing in sheep. Gene Ther 2006;13:1290-9. Crossref

30. Perri B, Cooper M, Lauryssen C, Anand N. Adverse swelling associated with use of rhBMP-2 in anterior cervical discectomy and fusion: a case study. Spine J 2007;7:235-9. Crossref

31. El Bialy I, Jiskoot W, Reza Nejadnik M. Formulation, delivery and stability of bone morphogenetic proteins for effective bone regeneration. Pharm Res 2017;34:1152-70. Crossref

32. Bagaria V. Bone morphogenic protein: Current state of field and the road ahead. J Orthopaedics 2005;2:e3.

33. Bilic R, Simic P, Jelic M, Stern-Padovan R, Dodig D, Pompe van Meerdervoort $H$, Martinovic S, Ivankovic D, Pecina $M$, Vukicevic S. Osteogenic protein-1 (BMP-7) accelerates healing of scaphoid non-union with proximal pole sclerosis. Int Orthop 2006;30:128-34. Crossref

34. Nie $\mathrm{H}$, Ho ML, Wang CK, Wang $\mathrm{CH}$, Fu YC. BMP-2 plasmid loaded PLGA/HAp composite scaffolds for treatment of bone defects in nude mice. Biomaterials 2009;30:892-901. Crossref

35. Seeherman H, Wozney JM. Delivery of bone morphogenetic proteins for orthopedic tissue regeneration. Cytokine Growth Factor Rev 2005;16:329-45. Crossref

36. D'Mello S, Atluri K, Geary SM, Hong L, Elangovan S, Salem AK. Bone Regeneration Using Gene-Activated Matrices. AAPS J 2017;19:43-53. Crossref

37. Shi P, Wang Q, Yu C, Fan F, Liu M, Tu M, et al. Hydroxyapatite nanorod and microsphere functionalized with bioactive lactoferrin as a new biomaterial for enhancement bone regeneration. Colloids Surf B Biointerfaces 2017;155:47786. Crossref

38. Gao $R$, Watson $M$, Callon KE, Tuari D, Dray M, Naot D, Amirapu S, Munro JT, Cornish J, Musson DS. Local application of lactoferrin promotes bone regeneration in a rat critical-sized calvarial defect model as demonstrated by micro-CT and histological analysis. J Tissue Eng Regen Med 2016. Crossref

39. Huh J, Lee J, Kim W, Yeo M, Kim G. Preparation and characterization of gelatin/ $\alpha-\mathrm{TCP} / \mathrm{SF}$ biocomposite scaffold for bone tissue regeneration. Int J Biol Macromol 2018;110:488-96. Crossref

40. Naskar D, Ghosh AK, Mandal M, Das P, Nandi SK, Kundu SC. Dual growth factor loaded nonmulberry silk fibroin/carbon nanofiber composite $3 \mathrm{D}$ scaffolds for in vitro and in vivo bone regeneration. Biomaterials 2017;136:67-85. Crossref

41. Dang M, Koh AJ, Jin X, McCauley LK, Ma PX. Local pulsatile PTH delivery regenerates bone defects via enhanced bone remodeling in a cell-free scaffold. Biomaterials 2017;114:1-9. Crossref
42. Carbone EJ, Rajpura K, Allen BN, Cheng E, Ulery BD, Lo $\mathrm{KW}$. Osteotropic nanoscale drug delivery systems based on small molecule bone-targeting moieties. Nanomedicine 2017;13:37-47. Crossref

43. Echave MC, Sanchez P, Pedraz JL, Orive G. Progress of gelatinbased 3D approaches for bone regeneration. J Drug Delivery Sci Technol 2017;42:63-74. Crossref

44. Korkusuz F, Korkusuz P, Ekşioğlu F, Gürsel I, Hasirci V. In vivo response to biodegradable controlled antibiotic release systems. J Biomed Mater Res 2001;55:217-28.

45. Emül $E$, Sağlam $S$, Ateş $H$, Korkusuz $F$, Sağlam N. Characterization of electrospun nanofibrous scaffolds for nanobiomedical applications. J Electronic Mater 2016:45;3835-41. Crossref

46. Yokota K, Matsuno T, Tabata Y, Mataga I. Evaluation of porous hydroxyapatite granule and gelatin hydrogel microsphere composite in bone regeneration. J Hard Tissue Biol 2017;26:203-14. Crossref

47. Shinto $\mathrm{Y}$, Uchida A, Korkusuz F, Araki N, Ono K. Calcium hydroxyapatite ceramic used as a delivery system for antibiotics. J Bone Joint Surg Br 1992;74-B:600-4.

48. Kankilic B, Köse S, Korkusuz P, Timuçin M, Korkusuz F. Mesenchymal stem cells and nano-bioceramics for bone regeneration. Curr Stem Cell Res Ther 2016;11:487-93.

49. Ciftci E, Köse S, Korkusuz P, Timuçin M, Korkusuz F. Boron containing nano hydroxyapatite (B-n-HAp) stimulate mesenchymal stem cell adhesion, proliferation and differentiation. Key Eng Mater 2015;631:373-8. Crossref

50. Kankilic B, Bilgic E, Korkusuz P, Korkusuz F. Vancomycin containing PLLA/beta-TCP controls experimental osteomyelitis in vivo. J Orthop Surg Res 2014;19:9:114. Crossref

51. Yang G, Liu H, Hu X, Chen Z, Friis TE, Wang J, Xiao Y, Zhang $S$. Bio-inspired hybride nonoparticles promote vascularized bone regeneration in a morphology-dependent manner. Nanoscale 2017;9:5794-805. Crossref

52. Kaito T, Myoui A, Takaoka K, Saito N, Nishikawa M, Tamai N, Ohgushi $\mathrm{H}$, Yoshikawa $\mathrm{H}$. Potentiation of the activity of bone morphogenetic protein-2 in bone regeneration by a PLAPEG/hyroxyapatite composite. Biomaterials 2005;26:73-9. Crossref

53. Hettiaratchi MH, Chou C, Servies N, Smeekens JM, Cheng A, Esancy C, Wu R, McDevitt TC, Guldberg RE, Krishnan L. Competitive protein binding influences heparin-based modulation of spatial growth factor delivery for bone regeneration. Tissue Eng Part A 2017;23:683-95. Crossref

54. Cahill KS, Chi JH, Day A, Claus EB. Prevalence, complications, and hospital charges associated with use of bonemorphogenetic proteins in spinal fusion procedures. JAMA 2009;302:58-66. Crossref 